\title{
As teorias e experimentos em ensaio sobre o fogo ${ }^{+*}$
}

Leonardo Olivel Correia ${ }^{1}$

José Otavio Baldinato ${ }^{1}$

Instituto Federal de Educação, Ciência e Tecnologia de São Paulo

São Paulo - SP

\section{Resumo}

$O$ estudo de fenômenos naturais de interesse social representa um dos objetivos da aprendizagem de ciências na Escola Básica. É de se estranhar, portanto, que o fogo, uma das mais úteis e fascinantes manifestações da Natureza, receba pouca atenção na ciência e quase nenhuma no ensino, como se percebe pela ausência de estudos aprofundados sobre este fenômeno nas coleções didáticas de química aprovadas pelo Programa Nacional do Livro Didático (PNLD 2015). O fogo, no entanto, já foi objeto de estudos da filosofia química no passado. Com o objetivo de resgatar a história do fogo enquanto objeto de estudo da química, neste trabalho propomos uma análise da obra An essay on fire, publicada em 1790 pelo celebrado filósofo de Genebra, Marc-Auguste Pictet. À luz da contemporânea historiografia da ciência, buscamos analisar de que forma as teorias do final do século XVIII explicavam tal fenômeno. Os resultados desta análise revelam aspectos de interesse sobre os modos de pensar dos químicos no contexto estudado. O texto de Pictet deixa claro, por exemplo, que a palavra fogo era empregada para designar não apenas a chama, mas um agente que seria responsável por diversos efeitos na estrutura dos corpos naturais, incluindo as dilatações, mudanças de estado e a própria decomposição química. Descrevendo séries de experimentos, o filósofo analisa o fogo sob quatro pontos de vista: Fogo liberado, calor específico, calor latente e fogo combinado. Todos os experimentos realizados pelo autor são precedidos por considerações teóricas e os resultados experimentais são

\footnotetext{
${ }^{+}$Theories and experiments of an essay on fire

* Recebido: maio de 2020. Aceito: junho de 2020.

${ }^{1}$ E-mails: correialeonardo843@gmail.com; baldinato@ifsp.edu.br
} 
usados como forma de aceitar ou recusar essas teorias que, muitas vezes, contrapõem concepções corpusculares e vibracionais na interpretação do fogo como o agente causal da sensação denominada calor. Concluímos que o estudo da obra de Pictet nos permite entender algumas características de como a ciência se desenvolve, destacando a importância da comunicação entre pesquisadores, a interdependência entre experimentos e teorias e o convívio com diferentes modelos para representar um fenômeno em estudo.

Palavras-chave: História da Ciência; Pictet; Essay on Fire; Fogo.

\section{Abstract}

The study natural phenomena of interest to society figures among the purposes of science teaching in Basic Education. It is surprising, therefore, that fire receives little attention in science and almost none in education. Even though fire most certainly represents one of the most fascinating manifestations of Nature none of the chemistry collections approved by the National Textbook Program (PNLD 2015) presents any in-depth study on it. But things were different in the past. In order to recover a particular detail of the history of fire as an object of study in chemical philosophy, in this paper we analyze the work An essay on fire, published in 1790 by the celebrated philosopher from Geneva, MarcAuguste Pictet. Based on the contemporary historiography of science we seek to analyze how fire was explained by some late 18th century theories. The results of this analysis reveal aspects of interest on chemists' style of thinking in the studied context. Pictet's text makes it clear that the word fire was used to designate not only the flame, but an agent responsible for several effects on the structure of natural bodies, such as dilation, changing states of aggregation and chemical decomposition itself. Describing series of experiments, the philosopher analyzes fire from four points of view: liberated fire, specific heat, latent heat, and combined fire. All experiments are preceded by theoretical speculations and results are used as means to accept or to reject such theories. It is also noteworthy that Pictet's approach often oppose corpuscular and vibrational assessments on fire as the causal agency to the effect that we call heat. We conclude that the study of Pictet's work allows us to access some nature of science features, highlighting the importance of communication between researchers, the interdependence 
between experiments and theories, and the coexistence of different models to represent a phenomenon under study.

Keywords: History of Science; Pictet; Essay on Fire; Fire.

\section{Introdução}

O fogo é um fenômeno natural dos mais interessantes e úteis. No ensino básico, o seu progressivo domínio pelos homens é amplamente reconhecido como um fator que teria levado a humanidade a novos estágios de desenvolvimento tecnológico e social (MORTIMER; MACHADO, 2013). É de se estranhar, portanto, que o fogo receba pouca atenção na ciência e quase nenhuma no ensino, o que se verifica pela completa ausência de um estudo aprofundado sobre o tema nas coleções de química aprovadas pelo Programa Nacional do Livro Didático (PNLD 2015).

Em termos da filosofia da ciência kuhniana, o estudo sistemático do fogo pode ser caracterizado como uma perda revolucionária na história da química (KUHN, 1962). No final do século XVIII, as novas interpretações trazidas por Lavoisier para os processos de combustão teriam transferido o foco das análises químicas para a medida das massas envolvidas nas transformações, deixando de lado um antigo apelo aos agentes que, na época, eram chamados de imponderáveis - dentre eles o fogo, a luz e a eletricidade. Em termos mais diretos, é como se o fogo, depois de controlado e aplicado aos meios de produção, tivesse perdido o status de objeto de estudo das ciências. No entanto, a historiografia contemporânea desmente essa versão da história da ciência, pois já são conhecidos documentos que atestam a permanência dos agentes imponderáveis em meio às teorias químicas mais bem discutidas na Europa até a década de 1840 (ALLCHIN, 1992; BALDINATO, 2015). Além disso, o próprio Lavoisier relacionou a luz e o calor entre os elementos - ou "substâncias simples" - que listou em seu Tratado Elementar de Química (LAVOISIER, 1789, p. 192).

A fim de reviver este momento da história da ciência em que o fogo era um objeto de estudo, resgatamos o livro publicado em 1790 sob o título Ensaio Sobre o Fogo, do suíço Marc-Auguste Pictet (1752-1825). Nesta obra o autor apresenta seu relato experimental sobre os fenômenos calóricos com ênfase em seu principal agente, um fluído invisível e possivelmente sem massa chamado de fogo. Neste artigo pretendemos apresentar as principais teorias de Pictet sobre o fogo e fazer um relato de seus experimentos, analisando qual o papel da experimentação em sua pesquisa. 


\section{Marc-Auguste Pictet}

A história dos Pictet está bem documentada em arquivos pessoais organizados pela Fundação dos Arquivos da Família ${ }^{2}$. Os Pictet têm origens que remontam a meados do século XIV. Seus primeiros ancestrais eram fazendeiros em Neydens, aldeia aos pés do monte Saleves, na França. Protestantes desde a reforma, participaram ativamente da política em Genebra, e mesmo depois da anexação à República Francesa, a influência dos Pictet se manteve. Além de políticos, parte dos familiares se dedicou ao estudo da filosofia natural, à religião e ao serviço militar.

Marc-Auguste Pictet nasceu em 23 de julho de 1752. Estudou direito na Academia de Genebra e formou-se advogado em 1774, mas nunca exerceu a profissão, preferindo se dedicar aos estudos na área da filosofia natural. Nesse campo, foi aluno de Horace-Bénédict de Saussure (1740-1799), celebrado professor de filosofia e história natural na Universidade de Genebra. Saussure é um dos mais renomados filósofos Suíços da sua época, tendo reconhecidas contribuições nas ciências meteorológicas, incluindo a invenção de aparatos como o higrômetro de cabelo, que será utilizado por Pictet em suas pesquisas. A relação de Pictet com seu mentor garantiu a ele a cadeira de seu mestre na Academia, quando Saussure se aposentou, em 1786 (EVANS; POPP, 1985). Neste mesmo ano Pictet tomou parte na redação do Journal de Geneve, periódico publicado pela Société des Arts, integrando uma equipe que contava com filósofos conceituados da época, como Saussure e Pierre Prévost (1751-1839). A participação de Pictet se deu até meados de 1791. Em 1790, publicou o livro Essai sur le feu (Ensaio Sobre o Fogo). Por volta de 1796, junto ao seu irmão, Charles Pictet (1755-1824), e ao amigo Fréderic-Guillaume Maurice (1750-1826), fundou e editou o periódico Bibliothèque Britanique, que publicava artigos científicos ingleses traduzidos para o francês. Em 1815 o periódico passa a incluir traduções de artigos publicados em outras nações e se torna a Bibliothèque Universelle (VAUCHER, 1825). Estes periódicos garantiram a Pictet certo reconhecimento internacional. Em 1798 o então imperador, Napoleão Bonaparte, anexa Genebra à França e em 1806 estabelece o bloqueio continental, que restringia a comunicação e as trocas de mercadorias com a Grã-Bretanha. Nesta época, o Bibliothèque Britanique foi de grande importância para a disseminação de trabalhos científicos e também da cultura inglesa na Europa Continental (BAHAR, 2001).

Influente pesquisador, Pictet participou como membro da Royal Society of London e como associado livre no Institut de France. Foi, ainda, um dos membros fundadores da Societé de Physique et d'Histoire Naturelle de Genebra (SPHN). A SPHN possui até os nossos dias o prêmio Marc-Auguste Pictet, que premia pesquisadores em início de carreira e que possuam trabalhos na área da História da Ciência. No ano de 1817, Pictet supervisionou a instalação de uma estação meteorológica no passo do Grande São Bernardo, nos alpes suíços

\footnotetext{
${ }^{2}$ Disponível em: <https://www.archivesfamillepictet.ch/>. Acesso em: 24 set. 2019.
} 
do cantão de Valais. Neste observatório, diariamente eram feitas análises que seriam publicadas mensalmente em seu periódico (AUBIN, 2009).

Pictet foi um homem de muitos contatos. Estima-se que tenha trocado mais de 3000 cartas ao longo de sua vida, mas o número exato é difícil de se estimar. Muitas dessas cartas registram sua atuação como disseminador da ciência. No compilado de cartas apresentado por Sigrist (2015, 2016), “Correspondance de Marc-Auguste Pictet (1752-1825)", encontramos diversas cartas nas quais ele trata do editorial da Bibliotèque Britanique e da Bibliotèque Universelle, de diálogos com o reitor da Academia de Genebra, além da divulgação de trabalhos científicos de autores menos conhecidos. Há ainda outro volume só com cartas recebidas do célebre naturalista Alexander Von Humboldt (1769-1859) numa compilação oferecida à Sociedade de Geografia de Genebra pelo professor Albert H. Rillet, neto de Pictet (LETTRES, 1868).

O nome de Pictet é citado em muitos artigos de caráter historiográfico, porém nunca como objeto principal de estudo, apenas como um coadjuvante nas histórias contadas sobre outros filósofos. O único trabalho que encontramos que traz Pictet como protagonista é o de Evans e Popp (1985), em que discutem o experimento da aparente radiação do frio realizado pelo filósofo suíço. Nas demais menções que encontramos sobre Pictet, os autores de tais artigos o apresentam como uma pessoa influente e de renome em função dos periódicos que editou na virada entre os séculos XVIII e XIX (LINDEE, 1991; WATTS, 2015) ou pelos seus trabalhos experimentais, que incluem, além do Ensaio sobre o fogo, outros sobre calorimetria e geologia (ALVES, 2015; CAROZZI, 1992; KUHN, 1958; RABKIN, 1987).

Trata-se, portanto, de um personagem ainda pouco explorado pelos estudos históricos da ciência, mas cujas relações e influência no contexto da filosofia natural europeia do final do século XVIII já foram identificadas.

\section{Sobre a obra}

Publicado originalmente no ano de 1790, o Ensaio sobre o fogo foi planejado para ser o primeiro volume de uma obra maior, intitulada Essais de physique. Contudo, o segundo volume, que receberia o nome de Ensaios sobre o ar, nunca foi publicado. Pela análise de algumas correspondências, principalmente entre Pictet e Benjamin Thompson, o Conde Rumford (1753-1814), notamos que as repercussões da Revolução Francesa comprometeram os planos do autor. A seguir apresentamos um trecho da carta a Rumford na qual Pictet explicita isto:

25 nov. 1796. Ao Conde Rumford: [...] Tomei a liberdade de enviar junto a esses exemplares [da Bibliothèque Britannique] um Ensaio sobre o fogo que publiquei há poucos anos e que foi agraciado logo em seguida com traduções em inglês e alemão. Talvez não haja nada de novo neste ensaio para um profundo conhecedor das questões Filosóficas como é o senhor, mas devo confessar que considero a semelhança do objeto em algumas das nossas pesquisas como uma espécie de 
afinidade com o senhor que tenho orgulho de reconhecer. Um segundo volume estava em estágio avançado quando Genebra foi revolucionada à francesa, e interrompi qualquer esforço que não se dirigisse à efetiva prevenção de maiores infortúnios (...) (SIGRIST, 2015, p. 418, grifos no original).

No prefácio, Pictet escreve que em certos momentos suas palavras se assemelham muito às ditas por Antoine Lavoisier (1743-1794) em seu Tratado Elementar da Química. Na página 22 , em uma nota de rodapé, ele volta ao assunto, afirmando que teve a felicidade de coincidir com o que Lavoisier apresenta na página 19 do primeiro volume de seu Tratado. Pictet afirma que suas palavras foram escritas dois anos antes da publicação da obra de Lavoisier, e que foram lidas pelos senhores Saussure e Jean Senebier (1742-1809), além de outros dois amigos (PICTET, 1791, p. ix).

Ainda em 1790 o livro foi traduzido para o alemão e, em 1791, para o inglês. O estudo que apresentamos neste artigo foi feito utilizando a edição traduzida para o inglês como fonte primária. Na capa do livro é informado ao leitor que a tradução foi feita com supervisão do autor. Também utilizamos a edição original em francês a fim de confirmar a fidelidade na tradução de alguns trechos do livro (PICTET, 1790).

A versão original do livro possui 212 páginas, enquanto a traduzida para o inglês traz 304. Esse aumento se dá pela diferença da tipografia empregada. Pictet dedica o livro à Royal Society of London e o organiza em nove capítulos, seguindo a estrutura abaixo:

Capítulo I: Introdução - Incertezas quanto à natureza do fogo - suas modificações podem ser consideradas sob quatro pontos de vista - fogo liberado - calor específico - calor latente - fogo em estado de combinação, ou fogo combinado.

Capítulo II: Fogo e luz guardam alguma analogia - propagação do fogo em um plano horizontal - razões para supor uma tendência para cima na propagação do fogo - aparatos para verificar tal tendência experimentalmente - confirmação dessa suposição.

Capítulo III: Vários experimentos sobre calor - descrição do aparato utilizado - efeito da cor e da natureza das superfícies em relação à sua reflexão do calor - experimento sobre a refração do calor - sua velocidade aparente reflexão do frio.

Capítulo IV: Descrição do aparato empregado para observar a transmissão de calor através de alguns fluídos elásticos.

Capítulo V: Experimentos preliminares - efeito da luz de velas refletido sobre um termômetro enegrecido - influências da luz do dia - exame do efeito dos lados do globo sobre a emanação calorífica das velas, e do calor médio do ar interno durante a continuidade destes experimentos - as vantagens deste aparato para experimentos manométricos.

p. 138 
Capítulo VI: Experimentos no vácuo seco ou úmido preenchido com vapor de éter - com fluído elétrico.

p. 158

Capítulo VII: Experimentos ligados à evaporação e à higrometria em geral.

Capítulo VIII: Experimentos a respeito da temperatura do ar em diferentes altitudes - circunstâncias notáveis que esses experimentos apresentam e consequências deduzidas a partir disto.

Capítulo IX: Experimentos sobre o calor produzido por fricção.

p. 283

(PICTET, 1791, p. xii-xiv)

Os principais temas estudados na obra são os fenômenos calóricos e o fogo. Um primeiro esclarecimento necessário é pontuar que a palavra fogo não remete apenas às chamas que surgem na combustão. Pictet a utiliza para nomear o agente causador dos fenômenos calóricos mais diversos. No decorrer do texto, o autor apresenta uma serie de experimentos a respeito dos fenômenos calóricos e a partir deles aborda como o fogo pode ser usado para explicar cada um destes fenômenos.

\section{A teoria do fogo}

Pictet apresenta as discussões acerca da natureza do fogo como prova de uma "humilhante verdade", qual seja, de que o conhecimento da ciência muitas vezes se restringe à mera descrição de fatos experimentais (PICTET, 1791, p. 3). Na percepção do autor, nem os maiores filósofos da sua época são capazes de entrar em acordo sobre o assunto. Esta discordância reside no fato de que teorias fundamentalmente diferentes e contrastantes explicam bem, dentro dos seus limites, os fatos experimentais conhecidos. Sem se comprometer de modo definitivo com nenhuma dessas teorias, Pictet afirma concordar com o proposto por Lavoisier e considerar o fogo não como substância, mas como um agente universal que é capaz de modificar as leis gerais que formam a matéria (PICTET, 1791, p. 3$6)$.

Pictet também conceitua calor como o efeito causado pela presença do fogo. O uso descuidado do termo calor por escritores, tanto em francês quanto em inglês, é colocado por Pictet como origem das muitas confusões a respeito do assunto. Calor seria apenas um efeito sensível, enquanto o fogo seria a causa deste efeito (p. 7).

Baseando-se na soma dos conhecimentos experimentais da época, Pictet classifica o fogo em quatro categorias: fogo liberado, calor específico, calor latente e fogo químico ou combinado (PICTET, 1791, p. 8).

O fogo liberado - também tratado na literatura da época como calórico livre, fluído ígneo ou fogo termométrico - é uma das formas mais gerais do fogo, é aquela que causa a sensação de calor. Quando produzido em certo lugar, por qualquer que seja o motivo, tende a se expandir ao redor de onde foi produzido através de emanações invisíveis, de acordo com 
certas leis. O fogo liberado tende a penetrar nos demais corpos que entram no caminho dessas emanações e essa penetração depende do corpo e de sua afinidade ${ }^{3}$ com o fogo.

Quando o fogo penetra nos corpos nota-se um aumento do volume. Assim, pode-se medir a presença de fogo liberado por essa dilatação nos corpos. A dilatação do mercúrio é proporcional à presença de fogo e seu uso em termômetros apresenta uma boa precisão. Porém, deve-se notar que o termômetro se limita a constatar as movimentações do fluído ígneo e não a quantidade absoluta de fogo nos corpos (PICTET, 1791, p. 9).

Outra característica importante do fogo liberado é a sua constante tendência ao equilíbrio, movendo-se da área de maior tensão para a de menor. Esta diferença de tensões é chamada de temperatura (PICTET, 1791, p. 10). O autor faz uma nota sobre o uso da palavra "tensão", explicando que a utiliza de maneira análoga à empregada no trabalho de Alessandro Volta (1745-1827) sobre o fluído elétrico (VOLTA, 1782). A fim de evitar confusões, o termo também pode ser entendido como "expansividade" (PICTET, 1791, p. 11).

$\mathrm{O}$ conceito de fogo liberado e de temperatura de Pictet nos permite interpretar o funcionamento do termômetro de mercúrio. O fogo presente no ambiente é absorvido tanto pelo vidro do termômetro quanto pelo mercúrio, de acordo com suas afinidades por este agente. $\mathrm{O}$ acréscimo de fogo em um corpo faz com que ele se expanda e, no caso do mercúrio líquido, podemos usar esta expansão para medir a variação de fogo liberado em determinados ambientes, utilizando assim, uma escala relativa arbitrária.

Para apresentar o conceito de calor específico Pictet faz uso de outro experimento mental, assumindo diversos objetos de mesmo volume e de mesma composição, dispostos ao redor de uma fonte de calor, todos à mesma distância do centro da emanação. Com o passar do tempo os materiais serão penetrados pelo fogo que está sendo liberado desta fonte. Em certo ponto estes corpos não serão mais penetrados e sua temperatura deixará de subir. Como os objetos são de mesmo tamanho e natureza, é de se esperar que se aqueçam ao mesmo tempo e que atinjam a mesma temperatura. Mas se esses objetos tiverem o mesmo peso e forem de naturezas diferentes, o tempo necessário para que alcancem o equilíbrio será diferente para cada um deles. Isso se justifica por que materiais diferentes apresentam permeabilidades ou, ainda, afinidades diferentes pelo fogo. Essa diferença de afinidade é chamada de calor específico (PICTET, 1791, p. 15). O autor prefere explicar a diferença de calores específicos entre os corpos utilizando o termo diferença de afinidades entre tais corpos e o fogo liberado (PICTET, 1791, p. 31). Para detalhar o conceito de calor específico, Pictet se utiliza de uma analogia com a diferença de permeabilidade à água de três corpos distintos.

\footnotetext{
3 O termo afinidade é empregado com diferentes sentidos ao longo do texto de Pictet. A forma mais elaborada deste conceito remete à interação de materiais diferentes que se combinam quimicamente, formando compostos de maneira espontânea ou com facilidade. Entretanto, nos primeiros experimentos relatados a afinidade é tratada como medida da permeabilidade ao fogo apresentada por diferentes materiais.
} 
Vamos pôr em uma bacia com água, ao mesmo instante, uma libra de esponja seca, uma libra de papel absorvente e uma libra de madeira porosa. Com o passar do tempo, todos estarão igualmente úmidos, [...].

Quando tirarmos essas três substancias da água, todas estarão aparentemente molhadas em mesmo nível, porém estarão longe de ter a mesma quantidade de água. O papel deverá ter absorvido mais que a madeira, e menos que a esponja.

Isso é o que acontece com várias substâncias de mesma massa e diferentes naturezas, inseridas em uma atmosfera calórica, e aquecidas até certa temperatura (PICTET, 1791, p. 17-18).

A conclusão, nas palavras do autor é a seguinte:

...eu acredito que essa comparação é tão exata, que estimo que a afinidade da água que molha é idêntica à afinidade do fogo que esquenta, [...] e como eu penso, não é nada mais que a afinidade de coesão, ou afinidade física, como eu chamo, em oposição à afinidade química ou eletiva (PICTET, 1791, p. 19).

Julgamos digna de nota a semelhança entre as analogias empregadas por Pictet e Lavoisier ao explicarem essa diferença dos corpos em sua capacidade de incorporar calor à sua estrutura. No Tratado Elementar de Química do filósofo francês encontramos o seguinte:

Se mergulharmos na água pedaços de diferentes madeiras, iguais em volume, de um pé cubico, por exemplo, esse fluído se introduzirá pouco a pouco em seus poros; eles incharão e aumentarão de peso, mas cada espécie de madeira admitirá nos seus poros uma quantidade de água diferente; as mais leves e porosas absorverão maior quantidade; as que forem compactas e comprimidas não deixarão penetrar mais que uma pequena quantidade. Enfim, a proporção de água que receberão dependerá ainda da natureza das moléculas constituintes das madeiras, da afinidade maior ou menor que têm com a água. [...] Poder-se-á, portanto, dizer que as espécies de madeiras têm capacidades diferentes para receber a água; [...]

O mesmo ocorre com corpos que são mergulhados no calórico; observando, contudo, que a água é um fluido incompressivel, ao passo que o calórico é dotado de uma grande elasticidade, [...](LAVOISIER, 2007, p. 36 / 1789, p. 19-20).

Pictet afirma que tal característica da natureza do fogo, o calor específico, não foi estudada pelos filósofos do passado. O autor afirma que o trabalho mais antigo conhecido por ele é datado de 1772, Modifications on the atmosphere, de Jean André De Luc (1727-1817). Este tópico foi estudado por diversos autores contemporâneos à Pictet de vários países, alguns citados são: Joseph Black, de Edimburgo; Lavoisier e Laplace, na França; Wilkie, na Suécia; e Chevalier Landriami, em Milão (PICTET, 1791, p. 24). Alguns desses autores construíram tabelas com o calor específico de diversas substâncias, muitas vezes tomando o calor específico da água como padrão. Porém, para Pictet, eles podem ter errado em suas análises por desconsiderarem o volume de suas amostras e simplesmente utilizarem a massa ou a quantidade de matéria. Para Pictet, é impossível analisar o calor específico dos materiais sem 
levar em consideração o volume que eles ocupam. Nas palavras de Pictet (1791, p. 27), uma libra de ar ocupa um espaço 800 vezes maior que uma libra de água, se ambos os espaços não estivessem ocupados, o primeiro já teria 800 vezes mais fogo que o segundo, tornando incabível a comparação unicamente baseada em massas iguais de diferentes materiais. Primeiramente Lambert e depois Saussure e Pictet realizaram experimentos nos quais, em uma câmara de vácuo com um termômetro, a rápida entrada de um pouco de ar fazia subir a temperatura em até dois graus. A explicação dada por Lambert e aceita pelo autor é que a entrada do ar traz consigo mais fogo para dentro da câmara. Mesmo no vácuo existe fogo desprendido de qualquer substância. A soma do fogo dentro da câmara com o agregado ao ar provoca um aumento de temperatura. $\mathrm{O}$ contrário também acontece, pois na exaustão da câmara, ela resfria. Porém com o passar de certo tempo, a temperatura dentro da câmara se equilibra novamente com o ambiente (PICTET, 1791, p. 28-29).

O terceiro ponto de vista sobre o fogo recebe o nome de calor latente. Esse aspecto surge nas mudanças de fase em que, mesmo com o aquecimento contínuo, a temperatura de um corpo se mantém constante até o fim da transformação física. Partindo de uma amostra de gelo, por exemplo, que está descongelando e formando água líquida, o termômetro se manterá a temperatura constante, mesmo sendo o sistema submetido a um fluxo constante de aquecimento. Todo esse fogo que entra no gelo e é insensível ao termômetro tem a finalidade de apenas mudar a forma de agregação das substâncias que compõem a matéria. Pictet afirma que a quantidade de fogo que não é registrada pelos termômetros durante esse processo é de grande magnitude. Utilizando a mesma quantidade de fogo no mesmo intervalo de tempo para aquecer água líquida a $0^{\circ}$, notaremos um aquecimento de $60^{\circ}$ na escala Réaumur. Já na água sólida, essa mesma quantidade de calor não levará a nenhuma mudança visível na temperatura. Essa mudança de estado físico também altera certas características das substâncias, como o calor específico. O aquecimento do gelo é mais rápido que o da água, isso porque o calor específico da água líquida é maior que o do gelo (PICTET, 1791, p. 34$38)$.

Por fim, existe o fogo que é combinado aos materiais por afinidades químicas, e neste estado, as características de fogo liberado não são mais notadas. Este fogo só é liberado nos processos de decomposição química ou por mudanças nos agregados que constituem a matéria. Quando isto ocorre o fogo é liberado e suas características termométricas retornam. O autor nos dá exemplos nos quais a mistura de certas substâncias libera ou absorve calor sem que ocorra reação química entre elas. Em misturas de água com ácidos, álcool ou cal, a modificação nos arranjos da matéria libera parte do fogo que estava agregado às substâncias iniciais. Na mistura de gelo e sal, o novo arranjo formado absorve fogo, causando a sensação de esfriamento (PICTET, 1791, p. 43-45).

A liberação de fogo combinado também ocorre em certas reações químicas. A combustão, por exemplo, é uma decomposição química e uma das mais abundantes formas de se produzir calor. O fogo que existe associado ao ar atmosférico adquire estado de liberdade e 
dois fenômenos ocorrem. Parte desse fogo se liga aos produtos sólidos ou aeriformes formados da queima, enquanto o restante se torna calor sensível (PICTET, 1791, p. 46).

Pictet também faz uma rápida discussão sobre a luz, afirmando que, aparentemente, calor e luz são partes de um todo e muitas vezes se apresentam em conjunto. Entretanto, o filósofo admite que isso não é sempre verdade, já que se observam fenômenos de emanações luminosas que não geram aquecimento.

Até aqui, o conhecimento da obra de Pictet nos desperta uma série de reflexões, tanto em relação às teorias da química quanto às características do próprio fazer científico. De início é preciso notar que a palavra fire possui outros significados na língua inglesa, podendo ser entendida como queimada ou incêndio, além de fogo. $O$ termo fire também possui outro significado na obra de Pictet, ele serve para nomear o próprio fluido ígneo, não somente as chamas presentes na combustão.

Uma das características distintivas da ciência é a mudança nos objetos de estudo. Nota-se que o fogo, no final do século XVIII ainda era um tópico de muito interesse dos pesquisadores. Essas mudanças nos objetos de estudo não ocorrem do dia para a noite. Durante a leitura da obra, principalmente na maneira como Pictet cita outros autores e suas diferentes opiniões a respeito do tema, fica claro que as conclusões estavam longe de ser unanimes. Essa conclusão é corroborada na análise feita por Evans e Popp em seu artigo (1985) ao demonstrarem que o tema dos fenômenos ígneos era estudado por muitos autores que, mesmo diante dos mesmos resultados experimentais, não se aproximavam de um consenso interpretativo.

Com a leitura da obra de Pictet e tendo em contraste o contexto científico da época, podemos ressaltar como a ciência é construída de forma coletiva pela comunidade científica de sua época. Ao longo da análise dos capítulos seguintes, notaremos que Pictet se apoia nos trabalhos de outros filósofos da época, principalmente Saussure, De Luc e Conde Rumford.

\section{Os experimentos sobre o fogo}

\section{V.1 Propagação do fogo liberado}

O primeiro experimento descrito por Pictet se desenrola a partir de reflexões sobre a natureza do fogo liberado. Um corpo quente tem excesso de fogo agregado às suas partes constituintes. Assim, esse fogo flui para fora do corpo espontaneamente a fim de equilibrar as tensões entre o fogo da atmosfera e esse no seu interior. Esse fenômeno de emanação de fogo por corpos quentes é explicado igualmente bem por duas suposições, como aponta Pictet. A primeira leitura possível do fenômeno considera a ocorrência de emanações reais, como se o fogo liberado fosse composto por diminutos corpúsculos que se movem do centro de emanação em direção às extremidades. A segunda linha de interpretação assume vibrações de um fluído ígneo, em analogia às ondas sonoras que se propagam no ar. Este fluído ígneo é entendido como um fluído elástico que ocupa todos os espaços e que é infinitamente leve ou, 
de fato, ausente de massa. Destas duas suposições, o autor prefere a primeira, por apresentar maior clareza ao entendimento.

Aceitando que o calor se espalha ao redor do foco de emanação, acredita-se que a intensidade deste calor diminuiria na razão inversa ao quadrado das distâncias. Lambert avaliou este fenômeno experimentalmente, confirmando esta razão. Pictet aponta que esta lei se aplica bem em planos horizontais, mas questiona se isso seria igual para propagações do calor em sentido vertical. $O$ autor se questiona, portanto, sobre uma possível "tendência antigravitacional" do fogo (p. 54).

É para testar essa ideia que o autor elabora o primeiro experimento descrito na obra. Seu projeto envolve o aquecimento de uma barra de metal posicionada na vertical, a fim de medir as temperaturas nas duas extremidades, comparando se o aquecimento é mais rápido ou intenso na extremidade superior. Pictet aproveita seu aparato para também fazer medições de como se dá o resfriamento desta barra quando o aquecimento é interrompido. Após o resfriamento, o aparato é invertido, girando a barra de metal de modo que a ponta inferior do primeiro teste seja agora a superior. Com isto o filósofo pretende verificar a diferença entre a sensibilidade dos termômetros posicionados em cada uma das pontas da barra metálica.

O aparato é composto por um tubo de vidro de 2 polegadas de diâmetro e 44 de comprimento, contendo uma barra cilíndrica de cobre de 4 linhas de diâmetro e 33 polegadas de comprimento ${ }^{4}$. As duas extremidades desse cilindro de cobre apresentam concavidades para proporcionar o encaixe de bulbos de termômetro. Dentro do tubo de vidro, tanto o cilindro de metal quanto os termômetros são fixados por arames "adequadamente adaptados para este propósito, e posicionados a distâncias iguais a partir do centro [do tubo]" (PICTET, 1790, p. 55). O tubo é acoplado a uma bomba de vácuo para evitar interferências do ar no espalhamento do fogo, pois segundo Pictet, ao se unir ao fogo, o ar torna-se mais leve e sobe, carregando consigo uma parte do fogo do ambiente. Essa combinação também diminui a quantidade de fogo liberado no meio (p. 53). O tubo de vidro é sustentado por uma moldura de madeira e todo o sistema é circundado por um papelão espesso com um buraco no centro, através do qual os raios solares são direcionados por uma lente com diâmetro de 12 e foco de 19 polegadas. O aparato é posicionado verticalmente e os raios solares aquecem a região central do tubo de vidro e do metal. Elaboramos uma representação esquemática dessa montagem na Fig. 1.

Pictet não especifica a escala de temperatura usada em suas medidas, mas por outras referências apontadas na mesma obra, acreditamos que a escala de trabalho empregada seja a de Réaumur. Quando o autor explica sobre calor latente, ele afirma que o gelo derrete a $0^{\circ}$ e a água entra em ebulição a $80^{\circ}$. Esses pontos, $0^{\circ}$ e $80^{\circ}$, são os pontos de referência da escala de Réaumur. Em um teste que apresentaremos à frente, o autor usa um termômetro na escala Fahrenheit, por ter uma maior precisão. A temperatura inicial marcada por este termômetro é de $47^{\circ} \mathrm{F}$, convertendo para Réaumur, cerca de $7^{\circ}$. A média das temperaturas iniciais dos

\footnotetext{
${ }^{4}$ A unidade de medidas linha equivale a $1 / 12$ de polegada, ou 0,2032 centímetros.
} 
outros experimentos que usam a escala em questão é de cerca de $7,6^{\circ}$. Concluímos que todas as temperaturas apresentadas pelo autor que não apresentam unidade estão na escala Réaumur.

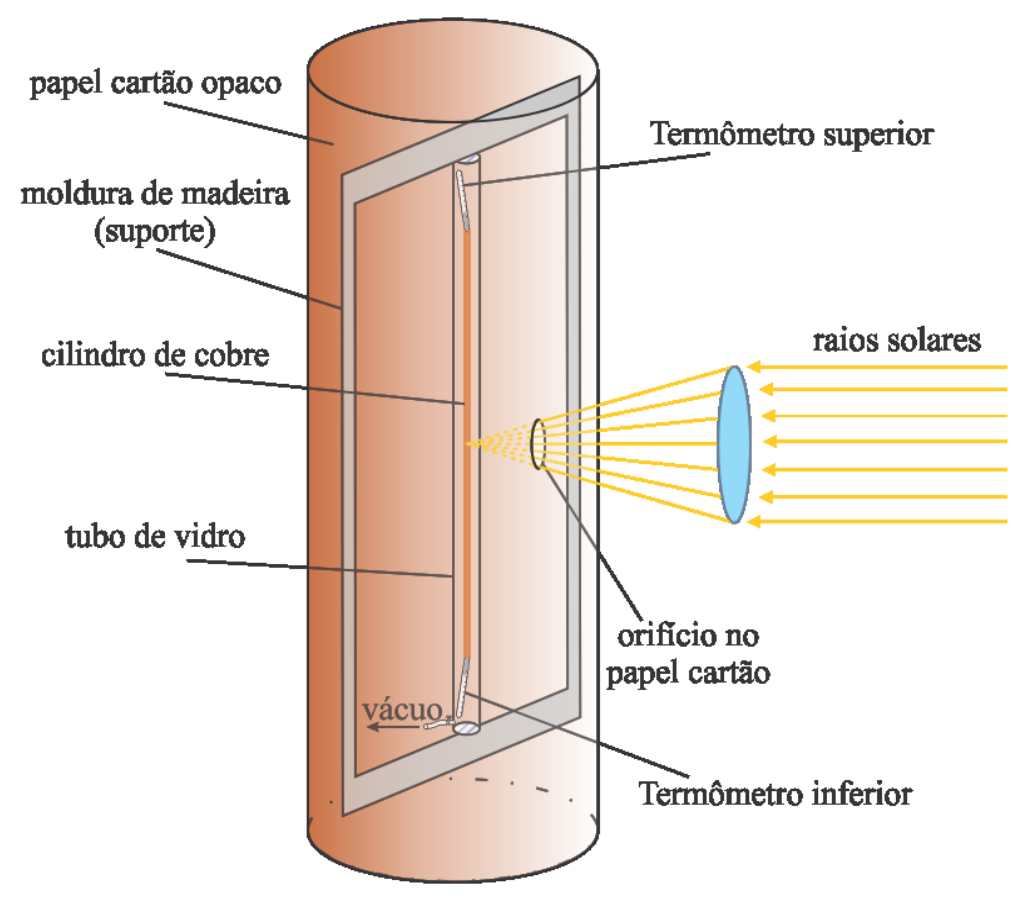

Fig. 1 - Representação do aparato para análise da tendência antigravitacional do fogo. Fonte: Os autores.

Os resultados são apresentados em tabelas. Nota-se que no mesmo intervalo de tempo, a temperatura máxima registrada foi maior no termômetro superior do que no inferior. O termômetro superior também indicou aquecimento mais rápido em todas as observações. Analisando-se a coluna das diferenças (Tabela 1) percebe-se que o aumento da diferença entre os termômetros foi gradual, porém irregular, Pictet, afirma que tal irregularidade pode ter sido causada, principalmente, por imprecisões nos termômetros e pela dificuldade de se fazer tais medidas. Após a última medição, Pictet suprimiu a fonte de calor tampando o buraco no papelão e fez medições do resfriamento dos termômetros. Logo após a retirada da fonte de calor, ambos os termômetros aumentaram a temperatura antes de começar a registrar resfriamento. Nas palavras do autor, aparentemente, a massa de fogo que entrou na barra de ferro foi muito mais abundante do que a que saiu (p. 63-64). 


\begin{tabular}{|c|c|c|c|}
\hline \multicolumn{5}{|c|}{ Tabela $1-$ Dados do primeiro aquecimento } \\
\hline $\begin{array}{c}\text { Tempo decorrido no } \\
\text { termômetro superior }\end{array}$ & $\begin{array}{c}\text { Temperatura } \\
\left({ }^{\circ} \text { Re) }\right.\end{array}$ & $\begin{array}{c}\text { Tempo decorrido no } \\
\text { termômetro inferior }\end{array}$ & $\begin{array}{c}\text { Diferença entre os } \\
\text { termômetros }\end{array}$ \\
\hline 0 min & 8 & 0 min & - \\
\hline 6 min & 11 & 6 min $30 \mathrm{seg}$ & $-30 \mathrm{seg}$ \\
\hline 7 min $10 \mathrm{seg}$ & 12 & $7 \mathrm{~min} 20 \mathrm{seg}$ & $-10 \mathrm{seg}$ \\
\hline $7 \mathrm{~min} 55 \mathrm{seg}$ & 13 & $8 \mathrm{~min}$ & $-5 \mathrm{seg}$ \\
\hline $8 \mathrm{~min} 45 \mathrm{seg}$ & 14 & $8 \mathrm{~min} 45 \mathrm{seg}$ & $0 \mathrm{seg}$ \\
\hline $9 \min 20 \mathrm{seg}$ & 15 & $9 \mathrm{~min} 30 \mathrm{seg}$ & $-10 \mathrm{seg}$ \\
\hline $9 \mathrm{~min} 55 \mathrm{seg}$ & 16 & $10 \mathrm{~min} 10 \mathrm{seg}$ & $-15 \mathrm{seg}$ \\
\hline $10 \mathrm{~min} 25 \mathrm{seg}$ & 17 & $10 \mathrm{~min} 48 \mathrm{seg}$ & $-23 \mathrm{seg}$ \\
\hline $11 \mathrm{~min} 02 \mathrm{seg}$ & 18 & $11 \mathrm{~min} 30 \mathrm{seg}$ & $-28 \mathrm{seg}$ \\
\hline $11 \mathrm{~min} 40 \mathrm{seg}$ & 19 & $12 \mathrm{~min} 10 \mathrm{seg}$ & $-30 \mathrm{seg}$ \\
\hline $12 \mathrm{~min} 15 \mathrm{seg}$ & 20 & $13 \mathrm{~min} 10 \mathrm{seg}$ & $-55 \mathrm{seg}$ \\
\hline $12 \mathrm{~min} 58 \mathrm{seg}$ & 21 & $13 \mathrm{~min} 55 \mathrm{seg}$ & $-57 \mathrm{seg}$ \\
\hline $13 \mathrm{~min} 52 \mathrm{seg}$ & 22 & $15 \mathrm{~min} 20 \mathrm{seg}$ & $-88 \mathrm{seg}$ \\
\hline $14 \mathrm{~min} 55 \mathrm{seg}$ & 23 & $16 \mathrm{~min} 55 \mathrm{seg}$ & $-120 \mathrm{seg}$ \\
\hline $16 \mathrm{~min} 02 \mathrm{seg}$ & 24 & $18 \mathrm{~min} 25 \mathrm{seg}$ & $-143 \mathrm{seg}$ \\
\hline $17 \mathrm{~min} 17 \mathrm{seg}$ & 25 & $19 \mathrm{~min} 40 \mathrm{seg}$ & $-143 \mathrm{seg}$ \\
\hline $18 \mathrm{~min} 45 \mathrm{seg}$ & 26 & $20 \mathrm{~min} 50 \mathrm{seg}$ & $-125 \mathrm{seg}$ \\
\hline $19 \mathrm{~min} 50 \mathrm{seg}$ & 27 & $22 \mathrm{~min}$ & $-130 \mathrm{seg}$ \\
\hline $21 \mathrm{~min} 05 \mathrm{seg}$ & 28 & $23 \mathrm{~min} 15 \mathrm{seg}$ & $-130 \mathrm{seg}$ \\
\hline $22 \mathrm{~min} 25 \mathrm{seg}$ & 29 & $24 \mathrm{~min} 35 \mathrm{seg}$ & $-130 \mathrm{seg}$ \\
\hline $23 \mathrm{~min} 10 \mathrm{seg}$ & 30 & $25 \mathrm{~min} 36 \mathrm{seg}$ & $-146 \mathrm{seg}$ \\
\hline $24 \mathrm{~min} 30 \mathrm{seg}$ & 31 & $27 \mathrm{~min} 10 \mathrm{seg}$ & $-160 \mathrm{seg}$ \\
\hline $25 \mathrm{~min} 35 \mathrm{seg}$ & 32 & $29 \mathrm{~min} 02 \mathrm{seg}$ & $-207 \mathrm{seg}$ \\
\hline $26 \mathrm{~min} 55 \mathrm{seg}$ & 33 & $29 \mathrm{~min} 55 \mathrm{seg}$ & $-180 \mathrm{seg}$ \\
\hline $28 \mathrm{~min} 15 \mathrm{seg}$ & 34 & $32 \mathrm{~min} 55 \mathrm{seg}$ & $-280 \mathrm{seg}$ \\
\hline $30 \mathrm{~min} 13 \mathrm{seg}$ & 35 & $34 \mathrm{~min} 50 \mathrm{seg}$ & $-277 \mathrm{seg}$ \\
\hline $32 \mathrm{~min} 10 \mathrm{seg}$ & 36 & $38 \mathrm{~min} 45 \mathrm{seg}$ & $-395 \mathrm{seg}$ \\
\hline $33 \mathrm{~min} 26 \mathrm{seg}$ & 37 & & \\
\hline $34 \mathrm{~min} 30 \mathrm{seg}$ & 38 & & $-101 \mathrm{seg}$ \\
\hline $38 \mathrm{~min} 45 \mathrm{seg}$ & 39 & & \\
\hline Média das diferenças, excluindo o último valor & \\
\hline
\end{tabular}

Fonte: Traduzido e adaptado de Pictet (1790, p. 60).

O aquecimento foi realizado novamente, no dia seguinte, na mesma hora do anterior. $\mathrm{O}$ vácuo ainda era o mesmo do experimento passado. $\mathrm{O}$ autor virou de ponta cabeça o aparato a fim de remover qualquer incerteza relacionada à sensibilidade dos termômetros. Outros dois termômetros foram adicionados do lado de fora do tubo de vidro, nas extremidades, a fim de medir a temperatura ao redor do aparato.

Pictet apresenta suas observações numa nova tabela, mas neste segundo teste a coluna das diferenças registra um resultado contrário ao obtido no dia anterior, ou seja, o termômetro inferior se aqueceu primeiro. A média da diferença entre os aquecimentos no primeiro teste foi de -101 segundos, já neste +47 . Pictet apresenta suas observações numa nova tabela, mas neste segundo teste a coluna das diferenças registra um resultado contrário ao obtido no dia anterior, ou seja, o termômetro inferior se aqueceu primeiro. A média da diferença entre os aquecimentos do primeiro caso foi de -101 segundos, já deste +47 . Pictet calcula a diferença entre essas médias sugerindo que assim seriam removidas as influencias 
individuais entre os termômetros. O resultado, -54 segundos, representa "o resultado das respectivas posições, ou a quantidade média na qual, mantidas todas as outras constantes inalteradas, o termômetro superior indica, mais rapidamente, o mesmo grau de elevação [de temperatura]" (PICTET, 1791, p. 67). A respeito dos termômetros exteriores, Pictet alega que eles não registraram diferença significativa, mesmo um deles estando posicionado na extremidade superior e outro na base do tubo.

$\mathrm{O}$ autor refaz o experimento com leves modificações nos encaixes dos termômetros, porém os resultados são semelhantes ao primeiro par de testes. Pictet concluiu, com base em seus resultados experimentais, que o fogo tem um movimento facilitado para cima, contrário à gravidade (p. 76). Nas palavras do autor:

Parece que podemos concluir justamente desses fatos, os quais se reforçam mutuamente, que o fogo realmente se move mais prontamente de baixo para cima do que na direção oposta, que é a comum para todos os corpos gravitantes; ou, talvez, que o fogo é mais leve do que um outro fluido aéreo, no qual está imerso; ou, por fim, que ele é essencialmente leve (PICTET, 1791, p. 80-81).

Por fim, Pictet aponta possíveis fontes de erro, como a bomba de vácuo utilizada, e afirma que o experimento deve ser realizado novamente com o tubo agora repleto de ar. Por fim, convida outros filósofos a repetirem tal experimento e verificarem este curioso fato. Podemos observar que o experimento de Pictet é pouco conclusivo. Ele fez apenas três pares de medições e o resultado na posição invertida foi diferente do obtido na posição inicial em todos os casos. $\mathrm{O}$ autor notou um padrão nessas diferenças e fez um tratamento interessante com seus dados experimentais. Ao subtrair a média dos valores em um par de medições em posições invertidas, Pictet estabelece um valor que representaria a diferença de sensibilidade entre os termômetros. Com isso ele faz com que o resultado experimental corrobore sua hipótese de que o fogo se move mais facilmente de baixo para cima. $\mathrm{O}$ experimento relatado neste subtópico tem como ponto de partida uma dúvida que surge de uma interpretação da teoria aceita pelo autor. Notaremos com os subtópicos seguintes que isto é um padrão na obra. Os experimentos são usados para responder questionamentos que surgem de inferências sobre o comportamento do fogo descrito pela teoria. $\mathrm{O}$ fato de registrar os tempos de aquecimento e resfriamento se deve à noção do movimento do fogo liberado. Como descrito pela teoria, o fogo se move de maneira a formar um equilíbrio, deslocando-se do ponto mais quente em direção ao mais frio ou, nos termos da época, da região com maior tensão para a de menor. Os tempos de aquecimento são relacionados com a entrada de fogo nos termômetros, e a contabilidade realizada por Pictet sobre essas relações de tempo despendido para o movimento do fogo em diferentes direções o permite reforçar sua hipótese inicial, sem, no entanto, dá-la por comprovada. 


\section{V.2 Reflexão do calor}

No início do capítulo 3, Pictet afirma que o fogo liberado pode penetrar os corpos materiais e produzir os diversos fenômenos térmicos, porém este fogo também pode ser refletido e este será o tema de estudo deste capítulo. Pictet cita os experimentos realizados por Saussure e publicados em Voyage dans les Alps como fonte de suas primeiras ideias sobre o tema (p. 86). O aparato utilizado por Pictet em todos os seus ensaios envolvendo este tema são semelhantes, porém, a cada novo teste alguma variação é feita a fim de atender novos critérios experimentais. De forma geral, o sistema consiste de dois espelhos côncavos, opostos um ao outro, distanciados por pouco mais de 3,6 metros (12 pés e 2 polegadas). No foco de um dos espelhos se encontra o bulbo de um termômetro e no outro se insere um corpo quente (p. 86-87). A Fig. 2 ilustra tal montagem.

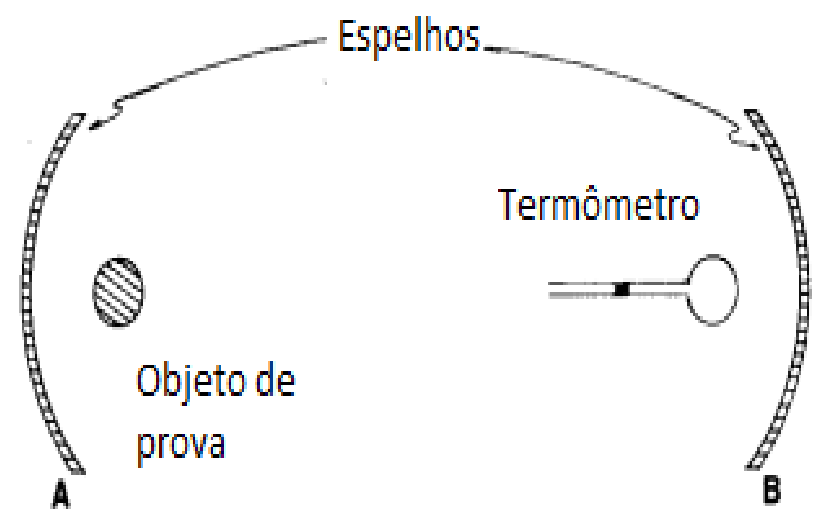

Fig. 2 - Aparato para testar a reflexão do fogo. Fonte: Traduzido e adaptado de Evans e Popp (1985, p. 738).

No primeiro ensaio, o corpo quente utilizado foi uma bala de mosquete aquecida de tal forma a emanar calor, mas nenhuma luz, mesmo quando no escuro. A presença deste corpo fez com que o termômetro subisse de $4^{\circ}$ para $14^{\circ}$ em cerca de 6 minutos (p. 87). No segundo ensaio o autor utilizou uma vela acesa no lugar da bala aquecida. Foram feitas duas medidas, registrando aumento de $4,6^{\circ}$ para $14,1^{\circ}$ no primeiro aquecimento e de $4,2^{\circ}$ para $14,3^{\circ}$ no segundo (p. 90). Os resultados destes dois primeiros ensaios são bem parecidos, porém existe uma diferença importante entre os dois corpos aquecidos. Nas palavras do autor, no primeiro ensaio a bala aquecida não emite luz, apenas calor. Já no segundo, a vela emite tanto luz quanto calor. Com isso em mente, ele se propõe a analisar qual a interferência da luz no aquecimento. Para tal, Pictet coloca entre os espelhos uma placa de vidro transparente. Seu objetivo era garantir a passagem da luz com pouca interferência, mas retendo o calor, ao menos em parte, já que parte do fogo que é liberado pela vela se une ao vidro, aquecendo-o. Neste terceiro ensaio com o uso da placa de vidro primeiro se realizou um aquecimento como o feito anteriormente utilizando a vela. $\mathrm{O}$ aquecimento foi de $2^{\circ}$ para $12^{\circ}$. Quando o 
termômetro se encontrou estacionário a placa de vidro foi colocada entre os espelhos, e com o passar de 9 minutos a medida no termômetro caiu para $5,7^{\circ}$. Com a retirada da placa de vidro, a temperatura indicada pelo termômetro voltou a subir, alcançando $11^{\circ}$ (p. 91-92).

Ainda abordando o efeito da luz no aquecimento, Pictet se questiona se realmente a bala de ferro não emite luz, talvez ela esteja emitindo luz que os olhos humanos não captam, mas que porventura pode ser sentida por órgãos mais sensíveis que os nossos (p. 93). A fim de remover a luz refletida da questão, Pictet utilizará como fonte de aquecimento uma massa de 62 gramas ( 2 onças e 3 drams) de água fervente. A água fervente tem ainda outra vantagem, já que é uma fonte de calor constante. Por outro lado, a água fervente não produz um efeito térmico tão considerável quanto o obtido com a vela ou com a bala de metal aquecida. Por isso a distância entre os espelhos foi reduzida para 3,20 metros (10 pés e 6 polegadas) e foi utilizado outro termômetro, mais sensível, na escala Fahrenheit. Neste quarto ensaio, sob essas condições, o termômetro inicialmente se encontrava em $47^{\circ} \mathrm{F}$ e se aqueceu até aproximadamente $50^{\circ} \mathrm{F}$ em dois minutos de aquecimento. Logo em seguida, a massa de água foi retirada do foco do espelho, o que resultou numa diminuição de temperatura registrada pelo termômetro (p. 93).

Neste ponto, Pictet estava confiante sobre a natureza reflexiva do calor. Com o objetivo de confirmar se o calor, da mesma maneira que a luz, é mais absorvido por corpos negros, repetiu o experimento narrado acima, porém enegreceu o bulbo do termômetro. Com isso notou que o aquecimento foi mais rápido, porém, a intensidade do aquecimento não foi maior do que a registrada pelo termômetro com o bulbo limpo (p. 94).

Para melhorar seus resultados, Pictet passa a utilizar um termômetro de ar, mais sensível que os outros usados até agora. Cada grau deste termômetro equivale a 1\%/24 da escala Réaumur (p. 97-103).

Pictet realiza ainda uma série de novos aquecimentos utilizando a massa de água fervente, dessa vez com a intenção de analisar de que forma o calor interage com diversas superfícies. Para isso, posiciona entre os dois espelhos alguns obstáculos de diferentes naturezas como um espelho plano, uma placa de vidro polido e papel cartão branco. Ora esses obstáculos têm o intuito de refletir o calor, ora absorvê-lo, e o autor conclui que todos diminuem a intensidade com que o termômetro se aquece.

Por fim, o último experimento realizado por Pictet surgiu a partir de um questionamento do professor de matemática da Academia de Genebra, o Sr. Louis Bertrand (1731-1812). Ele propôs a Pictet o experimento da reflexão do frio, que consiste de numa montagem bem semelhante à que discutimos até aqui. A diferença é que as fontes de calor que se encontravam no foco do espelho foram trocadas por corpos frios, neste caso, certa quantidade de neve. Estando os espelhos a uma distância de 3 metros (10 pés), Pictet registra ter observado rápida diminuição na temperatura até que se atingiu um valor constante. $\mathrm{O}$ autor não especifica a massa de neve empregada e nem quais foram as temperaturas iniciais e finais do experimento, mas afirma que, depois de atingido o equilíbrio térmico, adicionou ácido 
nítrico à neve e observou nova diminuição na temperatura. $\mathrm{O}$ experimento foi realizado uma segunda vez, com resultado semelhante (p. 117). A sugestão do Sr. Bertrand pressupunha o interesse de testar se o frio também não se propagaria seguindo as mesmas leis de condução que Pictet havia encontrado para o calor. Na visão de Pictet, entretanto, o que realmente ocorreu não foi a reflexão do frio, mas sim um novo exemplo de reflexão do calor. Neste caso, o corpo que emitia os raios caloríficos era o termômetro, por ser o mais quente no sistema de trocas de calor. O fogo liberado fluía, então, em direção ao espelho, convergindo sobre a massa de neve. Como o termômetro perde fogo para o meio, o volume do mercúrio diminui, registrando diminuição na temperatura (p. 118). A conclusão de Pictet é a que segue:

Este fenômeno oferece nada mais que uma prova final, se é que ela era necessária, da reflexão do calor. Eu concebo esse assunto da seguinte forma: Suponha $A$ e $B$, dois espelhos côncavos, dispostos numa sala a certa temperatura; vamos posicionar, no foco de $A$, um termômetro na mesma temperatura da sala, $e$ imaginemos que o foco de B contenha apenas certa quantidade de ar, na mesma temperatura da sala.

Vimos que todo corpo aquecido está, de alguma maneira, num estado forçado. Agora, o menor aumento que seja ocasionado sobre a temperatura do termômetro neste experimento fará com que ele deva ser considerado como um corpo quente se comparado a qualquer outro corpo mais frio. O seu fogo, portanto, tenderá a abandoná-lo, e se pudesse, se difundiria ao redor do termômetro na forma de emanações radiantes, que em grande parte se chocariam com o espelho A, em cujo foco está o termômetro, e seriam refletidas para o espelho B em raios paralelos que, por fim, convergiriam sobre o seu foco. Mas esse efeito é apenas potencial, porque estando o ar no foco de $B$ à mesma temperatura que o termômetro, seu fogo desenvolverá a mesma tensão que o fogo do termômetro no foco oposto, e resistirá a escapar com uma força precisamente equivalente à que o fogo do termômetro exercerá para chegar ao foco de B. Neste caso, portanto, tudo está em equilíbrio e o fogo não pode se mover, pois a resistência dos dois lados é igual à tensão.

Todavia, se no lugar do ar aquecido dispusermos no foco de B um corpo não apenas mais frio que o termômetro no foco A, mas que, como a neve ou o gelo, seja de uma natureza capaz de destruir a tensão do fogo que chega lá, então o curso do fogo do termômetro que era apenas potencial na suposição que acabamos de fazer, tornar-se-ia atual. A presença do corpo frio abriria uma espécie de golfo para o calor da sala. Isso absorveria mais poderosamente o calor do termômetro, à medida em que este chegaria como em um funil, pois o espelho A receberia cerca de um terço das emanações calorificas vindas do termômetro, e as refletiria ao espelho $B$, perdendo-se na neve do frasco em seu foco. [...] Portanto, o experimento feito com a neve não difere daquele feito com a bala ou com a massa de água fervente, se não pela direção das emanações caloríficas (PICTET, 1791, p. 119-122).

De acordo com Pictet, os resultados apresentados neste trecho são melhor explicados se entendermos os efeitos descritos não como a reflexão de uma emanação real, mas sim como a reflexão de uma vibração peculiar do fluído ígneo. No experimento anterior, da 
tendência antigravitacional, Pictet prefere o modelo de emanações reais, corpusculares. Contudo, para o fenômeno da reflexão o modelo de vibrações é mais satisfatório. Estas vibrações se assemelham às vibrações das ondas sonoras que podem ser refletidas da mesma forma (p. 123). Citando cálculos que consideram a área superficial dos espelhos e a distância focal, Pictet computou que cerca de 1/12 de toda a emanação liberada pelos corpos quentes chega ao foco do segundo espelho, concentrada de tal maneira que não ocorreria sem a ajuda da reflexão dos espelhos côncavos (p. 89-90).

Ressaltamos que o autor muda as variáveis do experimento e apresenta quais as vantagens e desvantagens de se usar cada uma delas, como por exemplo a fonte de aquecimento. Pictet também faz pequenas modificações em seus aparatos a fim de apresentar uma gama de possibilidades. Concluímos que Pictet valoriza ressaltar os detalhes da experimentação e isso vem ao encontro do objetivo da obra, que é apontar rotas experimentais para o estudo do fogo. Em sua conclusão sobre a aparente reflexão do frio, vemos como Pictet interpreta as observações experimentais e consegue usar a teoria do fogo para negar a hipótese proposta pelo seu colega da Academia e explicar tais resultados.

\section{V.3 Influências na absorção de fogo}

Nos capítulos V e VI, Pictet relata como a absorção de fogo é influenciada por dois fatores. O primeiro é a cor e o segundo é o meio em que o corpo está inserido. Nos experimentos destes capítulos ele utilizará um aparato de construção própria, que reproduzimos na Fig. 3.

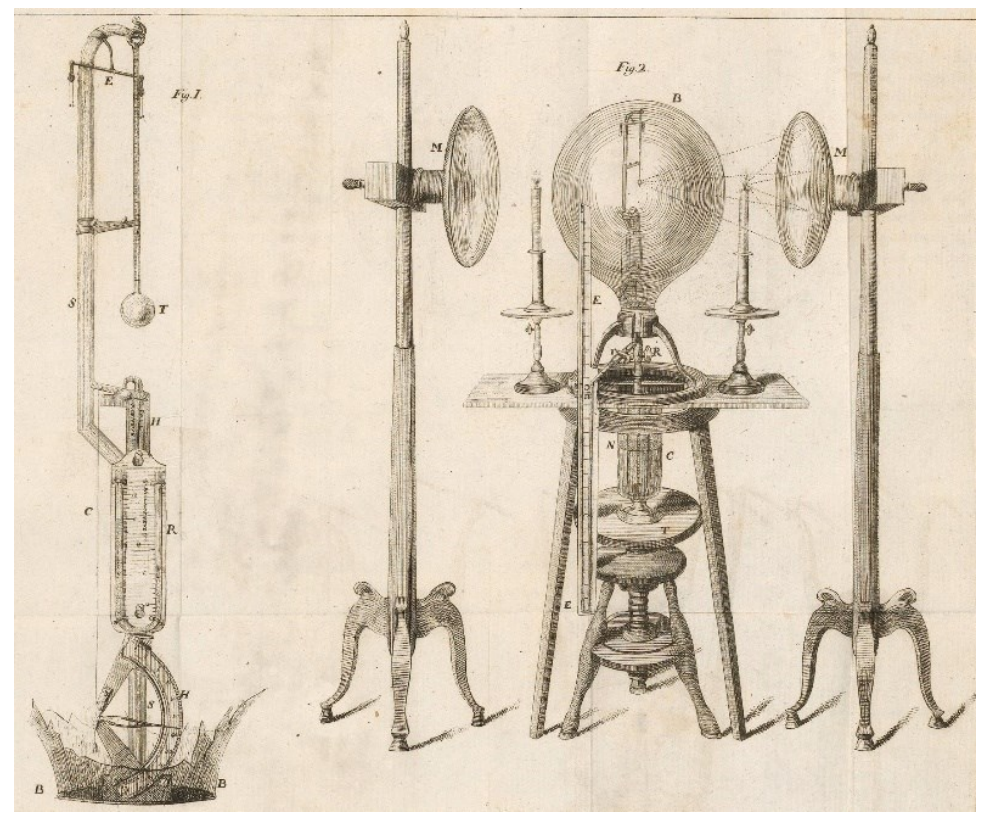

Fig. 3 - Aparato para avaliar as influências do meio. Fonte: Pictet (1790, apêndice). 
$\mathrm{O}$ aparato consiste de quatro instrumentos de medida, representados por letras no detalhe à esquerda da figura: o termômetro $\mathrm{T}$, o eletrômetro $\mathrm{E}$, o indicador de pressão $\mathrm{R}$ e um higrômetro de cabelo $\mathrm{H}$, sendo $\mathrm{C}$ o fio que detecta a umidade. Esses quatro indicadores são inseridos em um globo de vidro $\mathrm{B}$, mantendo o termômetro $\mathrm{T}$ exatamente no foco de dois espelhos côncavos. Mesmo parecendo complicado, este aparato apresenta boa robustez, sendo capaz de realizar diversos testes. O bulbo de vidro serve como um isolante para o termômetro, podendo submetê-lo a condições de vácuo, por exemplo.

Em experimentos anteriores Pictet observou que enegrecer um bulbo de termômetro aumentava a absorção de fogo. A fim de se certificar destas observações realizou uma série de aquecimentos alternando bulbos enegrecidos e limpos. Para isso utilizou o aparato descrito acima, porém sem o globo de vidro. Pictet registrou a temperatura e o tempo de cada um desses aquecimentos e depois fez o mesmo para o resfriamento dos termômetros. Como resultados, registrou que os termômetros com os bulbos enegrecidos se aquecem mais rapidamente e atingem temperaturas máximas maiores. Também anotou que os bulbos enegrecidos demoram mais para se resfriar. Mesmo quando Pictet coloca os dois termômetros sob a luz do sol, o termômetro enegrecido sempre registra temperaturas maiores. O autor afirma que essa característica de termômetros com cores escuras se aquecerem mais fortemente pode ser notada ao se comparar um termômetro de mercúrio com um de álcool tingido (de coloração vermelha). Nos termômetros de álcool, a temperatura registrada é levemente maior que nos termômetros de mercúrio quando expostos a ambientes com muita luz solar. Essa diferença diminui quando se trabalha em ambientes fechados (p. 145).

Pictet também relata seus resultados sobre como o meio em que está inserido um termômetro influência na absorção de fogo. $\mathrm{O}$ autor analisou quatro atmosferas diferentes dentro do bulbo de vidro: vácuo seco; vácuo úmido; éter vitriólico; e fluído elétrico. Pictet tentou fazer um experimento com vapor de álcool, mas não teve sucesso. Todos os experimentos relatados a seguir foram realizados no Gabinete de Física da Academia de Genebra. $\mathrm{O}$ autor garante que todas as precauções quanto a variações de temperatura no ambiente ao redor do aparato foram tomadas para evitar erros experimentais (p. 162).

O primeiro ensaio é realizado no vácuo. $\mathrm{O}$ autor se esforça para realizar o melhor efeito de rarefação e secura, mas admite ser impossível atingir um grau zero de umidade. Ele acende duas velas nos focos dos espelhos $\mathrm{M}$ e $\mathrm{M}$ e mede as temperaturas registradas durante $\mathrm{o}$ aquecimento, bem como o tempo necessário para se adquirir tal grau de aquecimento. Também registra a velocidade do resfriamento. Em seguida espera que o sistema retorne ao equilíbrio térmico com o ambiente e insere vapor de água no bulbo de vidro. Pictet chama este meio de vácuo úmido, procedendo seus registros que associam o tempo aos valores do aquecimento e do resfriamento do termômetro nesta nova atmosfera.

Pictet apresenta uma tabela comparando os tempos necessários para o termômetro atingir cada grau de aquecimento em cada um dos meios. Pictet também teve a preocupação 
de registrar os valores de umidade indicados pelo higrômetro bem como a temperatura ambiente aferida pelo mesmo termômetro, antes e depois do experimento.

A temperatura máxima registrada no vácuo seco foi de $22^{\circ}$ e no vácuo úmido $21^{\circ}$. Porém o aquecimento foi mais rápido no segundo meio. Pictet interpreta que uma temperatura menor registrada no vácuo úmido é explicada pelo fato da umidade interceptar parte do calor irradiado. Porém o aquecimento mais rápido nesse meio foi atribuído a combustão irregular das velas utilizadas no aquecimento. $\mathrm{O}$ autor afirma que uma replicata deste experimento $\mathrm{o}$ mostrou um aquecimento mais rápido no vácuo seco.

O resfriamento foi mais rápido no vácuo seco, porém essa diferença é mais discreta do que no aquecimento. Pictet afirma que duas são as causas para isto. A primeira é que o vácuo úmido se aqueceu menos, logo é mais fácil de se resfriar. Já a segunda, o autor leva em consideração que o mesmo fenômeno que dificultou o aquecimento do termômetro no vácuo úmido (a afinidade entre o fogo e as moléculas de umidade), também dificulta a saída do fogo do termômetro. Pictet, em uma nota de rodapé, concorda com a conclusão apresentada por Benjamin Thompson em sua publicação na Philosophical Transactions de 1786. Thompson realizou uma pesquisa sobre a condutividade de calor pelo vácuo, ar seco e ar úmido. Mesmo sendo de naturezas distintas, os resultados experimentais de ambos os trabalhos são concordantes (PICTET, 1791; THOMPSON, 1786).

No ensaio seguinte o globo é preenchido com vapor de éter vitriólico, conhecido atualmente como éter etílico. Pictet afirma que o trabalho com o vapor deste éter é difícil, pois durante as medições da temperatura, parte do éter se liquefaz sobre o termômetro, dificultando as leituras. O autor afirma, em seu texto, que a água é parte constituinte do éter e parte dessa água é registrada pelo higrômetro. No aquecimento do vácuo úmido o higrômetro registrava um valor $93^{\circ}$. Neste ensaio com o éter o mesmo equipamento registrou $96^{\circ}$.

Para Pictet, o aquecimento do éter deveria ser mais lento, pois ele esperava que o fogo tivesse mais dificuldade para atravessá-lo em comparação ao vácuo úmido. Suas medições, no entanto, registram tempos totais de aquecimento muito semelhantes nos dois casos. Tanto o vácuo úmido quanto o éter alcançaram temperaturas máximas semelhantes. $\mathrm{O}$ autor argumenta que o ponto de partida para o aquecimento com o éter foi aproximadamente dois graus maior do que no vácuo úmido. Logo, o termômetro submetido ao meio de éter se aqueceu menos que aquele influenciado pelo vácuo úmido. Pictet justifica que estes resultados devem ser explicados pelo calor específico do éter ser mais baixo que o da água e porque o éter se mostraria pouco permeável ao fogo liberado, sendo um condutor térmico ruim (p. 180-182).

Por fim, Pictet, avaliou como o fluído elétrico interfere no aquecimento e resfriamento do termômetro. $\mathrm{O}$ autor não faz nenhuma conceituação sobre o fluído elétrico, mas se gaba por dispor de uma "excelente máquina elétrica", capaz de gerar faíscas elétricas que se propagam "a distâncias de até 15 polegadas a partir da extremidade do condutor" (p. 184-185). A disposição do aparato foi a mesma, a máquina elétrica possui um braço metálico 
que faz a comunicação da eletricidade para o globo de vidro previamente submetido à bomba de vácuo. Antes de realizar o aquecimento, Pictet testou se a eletricidade interferia com algum dos indicadores presentes no aparato. Durante 5 minutos de descargas elétricas, nenhum indicador se moveu. Inclusive o eletrômetro continuou registrando um valor de 0 unidades. Pictet supõe que o indicador permaneceu em repouso porque tanto o interior do globo quanto o ambiente ao redor dele estavam tomados por uma atmosfera elétrica densamente positiva, de modo que mesmo o mais sensível dos eletrômetros não poderia medir nenhum valor ( $\mathrm{p}$. 186). Pictet realizou dois aquecimentos, um com eletricidade e outro sem. Segundo Pictet, o efeito da máquina elétrica gerou um distúrbio na queima da vela, que fez com que ela queimasse de maneira inconstante nos aquecimentos que envolviam eletricidade. $O$ termômetro submetido ao fluido elétrico se aqueceu menos que o sob o vácuo, porém o aquecimento neste meio foi consideravelmente mais rápido.

Pictet afirma que isso pode ser explicado se considerarmos que a eletricidade causa um fenômeno térmico, que acrescido ao efeito das velas, aumenta a velocidade do aquecimento, mas não sua intensidade. $\mathrm{O}$ autor realiza este experimento mais duas vezes, variando o material do castiçal que segurava a vela. No primeiro teste, usou um castiçal de vidro, que segundo o autor, consegue isolar a vela da condução elétrica. No segundo teste, ele se utilizou do castiçal que havia usado nos outros experimentos, que não isolava a vela (p. 191).

Os resultados do experimento com as velas isoladas, para a surpresa de Pictet, foram contrários ao primeiro. O vácuo simples se aqueceu mais rapidamente e atingiu uma temperatura mais alta. Já os resultados do aquecimento com a vela não isolada são semelhantes aos do primeiro ensaio: o vácuo elétrico se aqueceu mais rapidamente, num grau menor, porém, dessa vez alcançou a mesma temperatura máxima que o vácuo simples.

Pictet notou que aparentemente a junção da eletricidade e do calor das velas produz um aquecimento mais rápido quando essas velas não estão isoladas do fluído elétrico. $\mathrm{E}$ também que o resfriamento é mais lento quando essas forças elétricas estão atuando. Pictet acredita que o fluído elétrico interage com o calor ou com a luz das velas e de alguma forma facilita o aquecimento. Porém, a explicação do autor não é conclusiva e ele mesmo acredita que em breve estas dúvidas seriam mais bem explicadas (p. 199-200).

A análise dos relatos de pesquisa apresentados até aqui nos permite notar alguns padrões na conduta experimental de Pictet. $\mathrm{O}$ autor valoriza as medidas de tempo entre cada mudança de temperatura. Possui o rigor metodológico de fornecer ambientes semelhantes para todos os experimentos realizados a fim de analisar a influência de apenas uma variável por vez. Depois, compara os resultados e avalia o comportamento do sistema em função da varável que foi mudada. Nestes experimentos, o autor dá atenção às medidas de temperatura, umidade e pressão antes, durante e depois do experimento. O eletrômetro acaba por receber pouca atenção, pois em todos os experimentos seu indicador permanece estacionário. 


\section{V.4 Experimentos relacionados ao higrômetro, à evaporação e ao manômetro}

O higrômetro de cabelo é foco dos inquéritos de Pictet no Capítulo VII. Este equipamento foi desenvolvido por seu amigo e professor, Horace-Bénédict de Saussure. Seu princípio de funcionamento é baseado no alongamento dos fios de cabelo promovido pelo aumento da umidade do ambiente. Um fio fica preso em um ponto fixo e sustenta um pequeno peso móvel. A posição deste peso varia, verticalmente, de acordo com o comprimento do fio de cabelo, que aumenta ao absorver umidade do ar. Segundo Pictet, o equipamento é de grande sensibilidade e registra rapidamente as variações da umidade no ar.

As medidas apresentadas pelo higrômetro variam com a temperatura. Nos termos do autor, à medida que a temperatura diminui, também diminui o fogo presente ao redor do higrômetro, e isso favorece o registro de um maior índice de umidade. Isso ocorre, pois, no ar, os vapores de água se encontram diluídos no fogo liberado. Quando esse fogo desaparece, seja qual for a causa, os vapores não se encontram tão diluídos e podem se ligar ao fio de cabelo do higrômetro. Disso se infere que as forças de afinidade que unem o fogo e o vapor de água são mais intensas que as forças atrativas entre o fio de cabelo e a água. Pictet recorre a interpretações dadas por Saussure para justificar que existe uma diferença nas forças de atração e afinidade, entre o ar atmosférico e o fio do higrômetro, que é alterada pela presença ou ausência de fogo (p. 204).

Porém Pictet notou uma exceção a esse comportamento enquanto trabalhava com vapor de água no vácuo. O mesmo globo apresentado no experimento anterior, previamente submetido a vácuo, foi preenchido com vapor de água. Um termômetro na sala onde o experimento foi realizado registrava $4^{\circ}$ de temperatura. O higrômetro registrava $98^{\circ}$ de umidade. Pictet, então, moveu o aparato para outra sala, onde outro termômetro indicava $0^{\circ}$ de temperatura. Com o passar de quatro minutos, a indicação do higrômetro desceu para $91^{\circ}$, e com o passar de mais tempo chegou a $89^{\circ}$. Depois de mais vinte e cindo minutos, voltou a subir e por fim se estabilizou em aproximadamente $97,5^{\circ}$. Pictet também notou a formação de orvalho no interior do globo de vidro (p. 208). Em seguida, o aparato foi movido para uma terceira sala onde a temperatura era de $6^{\circ}$. Quase instantaneamente o higrômetro registrou $99,3^{\circ}$ de umidade. Com o passar do tempo, o orvalho formado evaporou e o higrômetro se estabilizou em $90^{\circ}$.

Nesse relato, Pictet notou um comportamento inverso ao esperado por Saussure. Primeiro, quando moveu o aparato para uma sala mais fria, o higrômetro registrou diminuição na umidade. Já quando o aparato foi para uma sala mais quente, houve aumento no registro da umidade (p. 209). Pictet afirma que para entendermos o que ocorreu nesse ensaio é preciso imaginar que dentro do globo há apenas vapor de água, fogo e o cabelo do higrômetro. $\mathrm{O}$ cabelo é fixo e imóvel, já o vapor de água e o fogo podem se mover de maneira livre, de acordo com certas leis. $\mathrm{O}$ fogo apenas se move buscando o equilíbrio, do lugar mais quente para o mais frio. $\mathrm{O}$ vapor de água se move em direção aos corpos com maior afinidade ao fluído aquoso. Quando o globo estava na primeira sala, a $4^{\circ}$ de temperatura, e não havia 
orvalho formado, pode-se dizer que tanto o fogo quanto o cabelo estavam em equilíbrio térmico com o meio, e em equilíbrio relativo à quantidade de água dissolvida em ambos. No momento em que o globo foi movido para uma outra sala, com temperatura mais baixa, o equilíbrio térmico foi rompido e o fogo inicia o movimento de reequilíbrio, indo do centro do globo de vidro para as extremidades. Nesse movimento ele carrega consigo a água que estava diluída nele. Quando o fogo encontra as paredes do globo, o vapor de água se condensa. Seria esse movimento o que gerou a diminuição da umidade registrada pelo higrômetro, no primeiro momento. $\mathrm{O}$ contrário ocorreu quando o aparato foi movido para uma sala mais quente, com o fogo se movendo das extremidades para o interior do globo e carregando consigo a água, e o higrômetro nota esse aumento na umidade (p. 214-216).

A respeito do fenômeno da evaporação, Pictet admite que suas observações o levaram a crer que o fogo é o único agente participante, contradizendo a crença de que o ar atmosférico funciona como um tipo de solvente químico. Ele afirma que as evaporações são facilitadas quando feitas no vácuo (p. 222) e isso pode ser facilmente observado quando se estuda o manômetro de mercúrio. Em frascos rarefeitos de ar e com mercúrio em seu interior, quando expostos a luz solar, por exemplo, é comum ver que parte do líquido evapora e se condensa em gotas na parte superior do tubo, que depois de certo tempo voltam a cair dentro do recipiente (p. 221).

\section{V.5 Temperatura do ar atmosférico}

Durante o capítulo VIII Pictet realiza alguns inquéritos a respeito do fogo presente no ar atmosférico. Ele afirma que os experimentos relatados nesta obra foram realizados entre 1778 e 1779. Grande parte dos resultados também foram publicados no quinto volume do Histoire de la Terre, de De Luc. Pictet ainda afirma que os experimentos dessa natureza que envolvem o barômetro foram realizados e seriam publicados em um segundo Ensaio. Acreditamos que este segundo ensaio seria o próximo volume de sua obra que, como ressalta a pesquisa de Sigrist (2015), nunca se concretizou.

O objetivo do primeiro experimento apresentado é medir a temperatura real de uma coluna de ar atmosférico. Para isso, Pictet precisaria medir a temperatura de diversos pontos de um estrato de ar. Essas medidas poderiam ser feitas usando um balão meteorológico, mas os erros associados a essa metodologia são muito grandes. Pictet, então, faz uso de um longo poste com termômetros a diferentes alturas. O poste comporta um sistema de polias que facilmente podem locomover os termômetros do topo até o nível do chão, para que se possa ler os registros de temperatura.

Pictet relata a utilização de um poste de aproximadamente 23 metros de altura (75 pés). O termômetro mais alto estava disposto de tal maneira a nunca se alinhar à sombra do poste. Outro termômetro, que se encontrava a 5 pés de altura, era movido à medida que o sol se movia, a fim de sempre permanecer na sombra do poste. Vários outros termômetros foram dispostos a diferentes alturas e, por fim, havia um termômetro com o bulbo enterrado sob a 
terra na base do poste (p. 246-248). O experimento consiste na leitura das marcações de todos os termômetros em intervalos de meia hora. Pictet afirma que para se traçar uma lei geral da temperatura de uma coluna de ar, um poste mais alto seria necessário (p. 252).

As medidas foram feitas desde o início do dia, antes do nascer do sol, até o nascer do sol do dia seguinte. Todos os termômetros concordavam em uma diminuição da temperatura à medida que o nascer do sol se aproximava, atingindo, neste momento a menor temperatura registrada. Em seguida, todos os termômetros registraram aquecimento até as três horas da tarde, sendo o ápice de calor do dia. Pictet notou que havia uma diferença que permanecia constante em certos horários do dia entre o termômetro no topo do poste e outro que se encontrava a 5 pés da base do poste. Do nascer até o pôr do sol, o termômetro a 5 pés registrava $2^{\circ}$ a mais em relação ao que se encontrava no topo. Durante o pôr do sol, os dois registravam a mesma temperatura. Porém, ao longo da noite essa diferença de $2^{\circ}$ era o oposto, com o termômetro do topo registrando temperatura maior que o a 5 pés. Pictet ainda observou que o termômetro enterrado apresentava, de noite, as maiores medidas de temperatura.

Segundo o autor, a terra retém fortemente o fogo recebido ao longo do dia. Pictet usa a ideia da diferença de intensidade dos raios solares ao longo do dia para explicar a variação dos termômetros. Também usa a evaporação do orvalho para explicar o porquê de os termômetros indicarem uma diminuição na temperatura momentos antes do sol nascer. $\mathrm{O}$ fogo liberado que vem dos raios solares, ao encontrar o orvalho deixa de ser sensível e se torna fogo de evaporação (latente), porém, com mais tempo ocorre maior incidência dos raios solares e a quantidade de fogo liberado é maior (p. 259-263).

Ainda neste capítulo Pictet recorre novamente às ideias de Saussure para discutir a diferença entre os tipos de vapores existentes. Ele afirma que os vapores podem ser classificados em três tipos de acordo com sua forma de dispersão no ar ambiente. A primeira classe é a dos vapores elásticos puros, que são invisíveis no ar ambiente. O próprio ar faz parte dessa classe. A segunda é a dos vapores vesiculares, que formam pequenas vesículas no ar de maneira heterogênea, como a neblina e as nuvens. E a terceira é a classe dos vapores concretos que formam gotas no ar, por condensação, ocasionando a chuva. Há diferenças na quantidade de fogo presente nessas três classes, da mesma forma que existe diferença na quantidade de fogo ligado à matéria nos três estados físicos. Saussure afirma que o vapor vesicular contém mais fogo que o vapor concreto, enquanto o vapor elástico puro tem mais fogo que os dois anteriores (p. 265). Ou seja, a quantidade de fogo no vapor que está prestes a se tornar chuva é menor que na neblina, que por sua vez é menor que no ar atmosférico.

Outra questão que este experimento aborda é a progressão média do calor do ar atmosférico ao longo de um dia em diferentes estações do ano. Pictet afirma que, para se atingir com perfeição essa progressão, deve-se realizar a soma de infinitas medidas ao longo de 24 horas e dividir pelo número de medidas. $\mathrm{O}$ autor realizou medidas durante o dia todo, a cada meia hora, obtendo um total de 48 observações. Ele afirma que a melhor forma de representar os resultados seria por meio de um gráfico de temperatura em função das horas do 
dia. Contudo, o próprio autor não ilustra tal gráfico, apenas afirmando que as linhas seguiriam um padrão de ziguezague. Normalmente, os experimentos de Pictet são realizados a fim de responder questões ou para comprovar aspectos da teoria. Nestes experimentos suas intenções eram aferir a "temperatura média real" (p. 245) de uma massa de ar, a interferência da neblina, nuvens e vento sobre a temperatura e a progressão de calor ao longo de um dia.

\section{6 Calor produzido por fricção}

Pictet acreditava que o calor produzido na fricção de dois corpos se dá pela liberação de fogo causada pela decomposição mecânica do ar presente entre os materiais, mas resultados experimentais o levaram a outra conclusão. De acordo com o próprio filósofo, o experimento que por fim mudou sua opinião tinha como objetivo avaliar a quantidade de calor gerada pela fricção de diferentes materiais de diferentes tamanhos, tanto no ar atmosférico, quanto no vácuo (p. 283). De maneira simples, o experimento é constituído por um sistema de três engrenagens conectadas de tal modo que a rotação do mecanismo resulte em 344 revoluções por volta da manivela de ativação. A última engrenagem possui um espaço no qual se insere um dos materiais a serem testados. Bem próximo a esse espaço se encontra um vão para fixação do outro material. As engrenagens giram e ocorre a fricção entre os corpos. Bem próximo desse ponto existe um pequeno termômetro que medirá o aumento da temperatura do ar. O livro não apresenta nenhuma imagem desse aparato (p. 284-285).

$\mathrm{O}$ primeiro teste descreve a fricção de bronze em bronze. $\mathrm{O}$ ensaio realizado no ar atmosférico produziu um brilho intenso nos materiais, já no vácuo esse brilho foi discreto. Os resultados preliminares mostraram que tanto no ar atmosférico quanto no vácuo, o calor gerado pela fricção não foi detectado pelo termômetro. O segundo teste foi a fricção de aço em aço. Houve um pequeno aquecimento do ar ambiente, de cerca de $0,3^{\circ}$. No vácuo esse aquecimento foi de $1,2^{\circ}$ (p. 292). No terceiro teste friccionou um metal com madeira e, em seguida, madeira com madeira. $O$ primeiro aquecimento registrado foi de $0,7^{\circ}$ e o segundo de $2,1^{\circ}$. O segundo experimento também foi realizado no vácuo e o aumento de temperatura registrado foi de $2,4^{\circ}$ (p. 293).

A fim de constatar qual a participação do ar atmosférico nesses aquecimentos, adicionou mais ar ao recipiente do aparato por meio de uma bomba. A fricção de metais com metais levou a uma série de medições registrando baixíssimo aquecimento ou aquecimento nenhum (p. 296). Pictet nos explica que o rápido giro das engrenagens carrega o fogo em direção aos termômetros e este fogo é produzido na decomposição mecânica do ar. O autor afirma inicialmente que os aquecimentos eram maiores no vácuo, pois o calor específico do ar atmosférico é maior que o do vácuo, absorvendo parte do fogo e diminuindo o fogo liberado, que pode ser sentido pelo termômetro (p. 292-294). Pictet notou que esta explicação não era suficiente quando realizou uma pequena modificação no aparato. Colocou um pequeno pedaço de algodão entre o termômetro e o material de bronze fixo que seria friccionado, a fim de evitar choques mecânicos que poderiam vir a danificar o termômetro. Para surpresa do 
autor, esse sistema registrou um aquecimento de quase $6^{\circ}$ quando bronze friccionava bronze. Realizou outros testes com outros materiais e em condições de vácuo. Esses aquecimentos eram muito maiores do que antes. E, como de costume, os aquecimentos eram mais intensos no vácuo. Todo esse calor era resultado da fricção do algodão com o bronze (p. 298). O autor afirma que com esses dados sua hipótese inicial passava a não explicar o fenômeno. $\mathrm{O}$ calor produzido por fricção não envolvia, portanto, a decomposição de nenhum componente do ar próximo aos corpos atritados. Pictet deixa esta questão aberta, apenas se perguntando quais poderiam ser as verdadeiras causas desses aquecimentos. Este é outro exemplo de como Pictet valoriza a experimentação e tem como objetivo principal apresentar uma série de questões ligadas a essa prática, convidando outros pesquisadores a tentarem respondê-las. Os resultados experimentais, neste caso, representaram vias para a aceitação ou rejeição de alguma teoria.

O último tema apresentado por Pictet diz respeito às faíscas que aparecem quando se risca uma pedra de pederneira (pelo atrito de um elemento mineral com outro metálico). Pictet afirma que tal efeito se dá por duas causas. A primeira é que a dureza do elemento mineral é tamanha que permite a extração de fragmentos do elemento metálico. A segunda é que o elemento metálico é altamente combustível. O atrito com a pedra é suficiente para remover pequenas lascas do metal de tal forma aquecidas que entram em combustão e decompõem o oxigênio presente no ar atmosférico. Esta decomposição libera o calórico livre que estava combinado ao gás oxigênio, e o metal é oxidado (p. 300-301). Esta é a única menção que Pictet faz ao gás oxigênio e ao calórico livre. Comparando os conceitos de fogo liberado, de Pictet, e de calórico livre, de Lavoisier, pode-se notar que as explicações são semelhantes, dando a entender que esses dois filósofos definiram o mesmo agente, apenas utilizando nomenclaturas diferentes.

\section{Considerações finais}

O objetivo deste trabalho era reviver um momento particular da História da Ciência em que o fogo constituía um objeto de estudo e analisá-lo com critérios diacrônicos, considerando os saberes conceituais negociados à época (ALFONSO-GOLDFARB; FERRAZ; BELTRAN, 2004; MARTINS, 2004). Para isso, tomamos como linha guia as teorias e experimentos presentes na obra de Pictet. Com a leitura deste ensaio sobre o fogo notamos que as próprias palavras têm sentidos diferentes dependendo do contexto científico. Nesta obra, a palavra fogo representa muito mais que as chamas presentes na combustão. Fogo, para Pictet, pode ser entendido como um elemento corpuscular capaz de se mover e penetrar os corpos promovendo efeitos variados como aquecimento, dilatação, mudança de estados físicos ou decomposição. Considerando manifestações sensíveis e insensíveis deste agente frente ao termômetro, o autor faz uso de dois conceitos de fogo para explicar fenômenos diferentes. É sabido que na época da publicação, os fenômenos de aquecimento eram muito estudados e havia diversas teorias que os explicavam (ALVES, 2015; EVANS; 
POPP, 1985). Notamos grande proximidade entre o conceito de fogo liberado, de Pictet, e de calórico livre, de Lavoisier. Ambos explicam de modo semelhante a dilatação dos corpos, as mudanças de estados e o conceito de calor específico, por exemplo. Pictet se agarra ao objetivo de apresentar novas rotas experimentais para que se aprofundem pesquisas sobre a natureza do fogo, e isso fica claro durante toda a obra. Também concluímos que na obra de Pictet os experimentos são usados como evidências ou, nas palavras do autor, provas que permitem avaliar qual concepção teórica é a mais adequada à interpretação de um conjunto de resultados. Todavia, essa escolha teórica circunstancial não implica na eliminação de modelos concorrentes. Sobre a teoria, notamos que muitas de suas explicações, principalmente as que tratam a respeito do movimento do fogo liberado, são completas e explicam coerentemente os fenômenos observados.

Diante de tantas vias de investigação abertas pela obra de Pictet, reforçamos a convicção de que o fogo é um fenômeno de grande interesse social e que merece um lugar no Ensino Básico. Pretendemos apresentar em outro trabalho a análise de uma experiência desenvolvida em sala de aula, na qual testamos as qualidades didáticas da obra de Pictet explorando dimensões da natureza da ciência a partir do registro histórico apresentado neste artigo.

\section{Referências bibliográficas}

ALFONSO-GOLDFARB, A. M.; FERRAZ, M. H. M.; BELTRAN, M. H. A historiografia contemporânea e as ciências da matéria: uma longa rota cheia de percalços. In: ALFONSOGOLDFARB, A. M.; BELTRAN, M. H. R. (Ed.). Escrevendo a História da Ciência: tendências, propostas e discussões historiográficas. São Paulo: Livraria da Física, EDUC, Fapesp, 2004. p. 49-73.

ALLCHIN, D. Phlogiston after oxygen. Ambix, v. 39, p. 110-116, 1992.

ALVES, E. A. Benjamin Thompson (Conde Rumford) e o experimento da radiação do frio. São Paulo: Pontifícia Unversidade Católica de São Paulo, 2015.

AUBIN, D. The Hotel that Became an Observatory: Mount Faulhorn as Singularity, Microcosm, and Macro-Tool. Science in Context, v. 22, n. 3, 2009.

BAHAR, S. Jane Marcet and the limits to public science. British Journal for the History of Science, v. 34, p. 29-49, 2001.

BALDINATO, J. O. Conhecendo a Química: um estudo sobre obras de divulgação do início do século XIX. 2015. Tese (Doutorado em Ensino de Ciências) - Universidade de São Paulo. São Paulo. 
CAROZZI, A. V. The history of petroleum geology and the geneva naturalists (1790-1815). Journal of Petroleum Geology, v. 15, n. 1, 1992.

EVANS, J.; POPP, B. Pictet's Experiment: the apparent radiation and reflection of cold. American Journal of Physics, v. 53, n. 8, p. 737-753, 1985.

KUHN, T. S. The Caloric Theory of Adiabatic Compression. Isis, v. 49, n. 2, p. 132-140, 1958.

KUHN, T. S. The Structure of Scientific Revolutions. Chicago: University Press, 1962.

LAVOISIER, A. L. Tratado Elementar da Química. Tradução: Laís dos Santos Pinto Trindade. São Paulo: Madras, 2007.

LAVOISIER, A. L. Traité Élémentaire De Chimie. Paris: Chez Cuchet, 1789.

LETTRES d'Alexandre de Humboldt a Marc-Auguste Pictet (1795-1824). Memóires de la Société de Géographie de Genève, v. 7, p. 127-204, 1868.

LINDEE, M. S. The American Career of Jane Marcet's Conversations on Chemistry, 18061853. Isis, v. 82, p. 8-23, 1991.

MARTINS, L. A.-C. P. História da ciência: objetos, métodos e problemas. Ciência \& Educação, v. 11, n. 2, p. 305-317, 2004.

MORTIMER, E. F.; MACHADO, A. H. Química. São Paulo: Scipione, 2013.

PICTET, M.-A. Essais de Physique. Tome $1^{\text {er }}$. Genève: Barde, Manget \& Co., 1790.

PICTET, M.-A. An Essay on Fire. London: Jeffery, E., 1791.

RABKIN, Y. M. Technological Innovation in Science: The Adoption of Infrared Spectroscopy by Chemists. Isis, v. 78, p. 31-54, 1987.

SIGRIST, R. Correspondance de Marc-Auguste Pictet (1752-1825) Tome III : Les correspondants britanniques. Version française inédite, 2015. Disponível em: $<$ https://independent.academia.edu/RenéSigrist/Books>. Acesso em: 24 set. 2019. 
SIGRIST, R. Correspondance de Marc-Auguste Pictet (1752-1825) Partie scientifique et technique Tome I: Les correspondants genevois. Version révisée, 2016. Disponível em: $<$ https://independent.academia.edu/RenéSigrist/Books>. Acesso em: 24 set. 2019.

THOMPSON, B. New Experiments upon Heat. By Colonel Sir Benjamin Thompson, Knt. E. R .S. In a letter to Sir Joseph "Banks, Bart, P. R. S. Philosophical Transactions, v. 76, p. 273-304, 1786.

VAUCHER, J. P. Nécrologie. Notice sur Mr. M. A. Pictet. Bibliothèque Universelle des Sciences, Belles-Lettres et Arts, v. 29, p. 65-88, 1825.

VOLTA, A. Del modo di render sensibilissima la più debole elettricità. Philosophical Transactions, v. 73, p. 237- 280, 1782.

WATTS, I. P. Philosophical intelligence: letters, print, and experiment during Napoleon's continental blockade. Isis, v. 106, n. 4, p. 749-770, 2015. 